\title{
SUBSÍDIOS PARA UMA FORMAÇÃO PROFISSIONAL CRÍTICO-REFLEXIVA NA ÁREA DA SAÚDE: O DESAFIO DA VIRADA DO SÉCULO
}

Mara Regina Lemes De Sordi*

Maria Helena Salgado Bagnato**

SORDI, M.R.L.de; BAGNATO, M.H.S. Subsídios para uma formação profissional crítico-reflexiva na área da saúde: o desafio da virada do século. Rev.latino-am.enfermagem, Ribeirão Preto, v. 6, n. 2, p. 83-88, abril 1998.

A mudança da lógica da formação dos profissionais de saúde é uma exigência frente aos desafios da nova ordem mundial. O presente estudo busca problematizar as bases do ensino crítico-reflexivo na área e sua contribuição para uma inserção dos profissionais no mercado de trabalho. Esta inserção deve ser regida pela ética da cidadania coletiva e deve estar disposta a enfrentar de forma organizada os interesses do projeto neoliberal.

UNITERMOS: formação profissional, ensino crítico-reflexivo, cidadania

\section{BUSCANDO ELEMENTOS PARA CONTEXTUALIZAR A QUESTÃO}

A prática e a educação na área da saúde, como realidades sociais, estão relacionadas com os processos de desenvolvimento econômico, científico e tecnológico. Desta forma, as alterações que vêm caracterizando o chamado período da pós-modernidade, onde o que se observa é o mundo globalizado, a ausência de fronteiras, o acesso aparentemente universal à informação, o endeusamento da tecnologia, a transformação do modo de produção e subseqüente retomada das qualidades necessárias aos trabalhadores para a inserção no mundo do trabalho (competitivo e exigente), estão requerendo "ajustes" dos aparelhos formadores, sob pena de que os egressos da escola não se encaixem às novas demandas geradas pela reestruturação dos interesses do capital (FRIGOTTO,1996).

Parece claro que as escolas em geral, e as da área da saúde por conseguinte, ponham-se a pensar sobre os rumos da formação de profissionais no limiar do novo século. Nossa proposta é problematizar sob que pano de fundo tal reflexão deva ocorrer, de modo a reafirmar compromissos com pressupostos básicos da cidadania, que devem reger a ética das relações humanas do ensino e da práxis dos futuros profissionais. Sem ignorar o fato de que toda formação profissional mantém estreita dependência com o mundo do trabalho, acabando por submeter-se, ainda que parcialmente, às exigências do mercado, cremos ser fundamental buscar garantir um primeiro componente da dimensão crítica da formação: reconhecer as novas roupagens que o capital assumiu para continuar perpetuando as desigualdades do modelo social que tem servido aos interesses dos mesmos grupos hegemônicos. Sem este primeiro nível de crítica, parece que a decantada insistência na valorização da formação crítica, mostrar-se-á infrutífera porque subestima (ignora?, dissimula?) as múltiplas conexões dos planos micro e macroestruturais, agora rejuvenescidas pela nova ordem social.

A escola, através da forma como organiza seu processo de trabalho, seleciona seus conteúdos e avalia seus alunos, pode contribuir para a disseminação de um conjunto de valores e atitudes questionáveis do ponto de vista político.

Em que pese algum avanço nos discursos dos docentes e dirigentes da área, responsáveis pelo delineamento de novos marcos conceituais nas propostas curriculares (que tem ocorrido não sem resistências e enfrentamentos entre os grupos que disputam o poder de definir os rumos da formação, guiados pela lógica decorrente de sua cosmovisão), ainda o que marca, indelevelmente, a prática na área da saúde, continua sendo a lógica tecnicista, a ênfase no saber e no saber-fazer, em detrimento muitas vezes do saber-ser. O destaque que fazemos respalda-se no significado desses traços nos

\footnotetext{
* Professora da Faculdade de Enfermagem da PUCCAMP e da Faculdade de Educação da UNICAMP, doutora em Educação, membro do grupo PRAESA

** Professora da Faculdade de Educação da UNICAMP, doutora em Educação, coordenadora do grupo PRAESA (Práticas de Educação e Saúde)
} 
profissionais, ao adentrarem ao mercado do trabalho, em uma sociedade cada vez mais impregnada pela falta da solidariedade e por uma competitividade de duvidoso valor ético.

Paradoxalmente, fala-se em formação críticoreflexiva, em competência política para transformar a realidade social. Só não se explica o que se quer transformar, e muito menos se esclarece qual o projeto histórico que orienta a opção por determinada transformação (FREITAS,1995).

É importante destacar que o ensino na área da saúde padece de longa data do tecnicismo, da forte biologização dos conteúdos selecionados como válidos e significativos à formação. Há sinais de luta tentando romper tal lógica, porém o ensino crítico vai precisar percorrer longo caminho, repleto de atalhos e armadilhas, até lograr algum impacto na prática.

Para que a formação na área possa dar o salto qualitativo que, timidamente, ameaça, há necessidade que se promovam rupturas em dois níveis:

1. alteração das concepções de Homem, Mundo, Sociedade e Educação dominantes nos docentes da área, criando novos paradigmas que dêem conta de esclarecer o que se entende por ciência e qual sua vinculação com o planejamento da práxis,

2. reorganização do trabalho pedagógico visando acelerar as transformações teórica e filosoficamente pensadas, dando-lhes concretude e visibilidade prática, aproximando discurso e ação.

Tais rupturas podem parecer fáceis, porém, o que temos presenciado ao discutir a prática pedagógica com docentes da área da saúde, é um sem-número de contradições, um amontoado de boas intenções, no mínimo inócuas do ponto de vista da real transformação. Um dos equívocos mais freqüentes é a proposição de inovações nas práticas de ensino, concebidas como tentativas de evidenciar avanços. O que elas escondem, entretanto, é a manutenção das concepções anteriores que permanecem vivas e determinando a lógica da formação. Assim, a mudança aparente e em aspectos não substantivos, tem servido como força desaceleradora para que docentes e alunos se apropriem dos instrumentos e habilidades fundamentais para uma leitura do mundo em que estão engajados e no qual podem, potencialmente, intervir no sentido de transformá-lo de forma radical (na raíz). Outro obstáculo comumente identificado, é a separação entre a dimensão técnica e política na operacionalização das propostas pensadas pelos educadores da área. Como se existissem dois momentos, clara e artificialmente distintos: o da teoria e o da prática. No primeiro espaço, onde se permitem elocubrações, cabe a reflexão política. No segundo momento, a hora de praticar a profissão, congela-se a política e o que importa é o exercício da prática profissional, nos moldes do ensino tradicional, asséptico, porém competente para os fins a que, dissimuladamente, se propõe.

Esta dicotomia tem servido, em nosso entendimento, para que a grande massa dos egressos da área da saúde adentrem ao mercado de trabalho, ávidos por exibir suas habilidades cognitivas e psicomotoras, o seu domínio da tecnologia e, simultaneamente, sua pequena familiaridade com as questões de fundo social. Parecem desapegados dos compromissos éticos que deveriam reger as relações humanas na sociedade. O que importa é competir, vencer individualmente, negando pelas ações, a possibilidade de se construir a cidadania coletiva.

Uma particularidade do atual momento histórico, pode nos colocar em situação favorável para alterar essa lógica dominante na formação. A sociedade de que falamos, está contida num mundo globalizado onde se privatizam os lucros e se socializam as misérias. Há, portanto, uma ampliação das carências de ordem material, psicológica e afetiva, uma extensão das doenças sociais em meio a ilhas de modernidade. E isto não nos pode pegar desprevenidos. O mercado hoje está desejoso de profissionais com qualidades diferentes, que saibam agir, tomar decisões, usar da criatividade para solucionar problemas. A partir de agora, as escolas vão ser avaliadas noutra matriz, que evidenciará as marcas que deverão ser imprimidas nos futuros egressos e que corresponderão ao padrão de competência da pós- modernidade. Isto pode acelerar o desabrochar de experiências de ensino propulsoras destas potencialidades. Pode significar um avanço positivo na formação, desde que não se perca de vista o outro nível da dimensão crítica por nós já aludido. Não se trata de ampliar a criatividade, garantir a autonomia do pensamento, transformar a relação do aluno com o conhecimento e manter a chama da curiosidade intelectual acesa, simplesmente. Isto, hoje, já nos é sancionado pelo sistema! O que pode fazer diferença é o "para que e para quem" usaremos estas nossas capacidades, anteriormente adormecidas e que, ao serem despertadas, podem e devem ser postas a serviço dos interesses maiores da sociedade. A superação do modelo fordista rompe com os padrões que impregnaram as práticas escolares (incluindo as da saúde), visando uma formação voltada para um processo produtivo parcializado, dicotomizado, alienado e alienante. Hoje, frente à nova ordem mundial, há uma forte tendência para recomposição das atividades subdivididas (ainda que remanesça a lógica excludente do processo). Diante dessas considerações, surgem perguntas inevitáveis:

- É possível delinear estratégias que aproveitem ao máximo as potencialidades de autonomia do processo de educação, na direção de maior compromisso social e ético por parte dos egressos na área da saúde?

- É preciso mudar, radicalmente, a forma de organização 
do trabalho pedagógico, rompendo com a "fôrma" que nos tem feito prisioneiros de um projeto, para produzirmos transformações, verdadeiramente significativas?

- É necessário repensar as práticas avaliativas que realizamos visando reafirmar nossos novos objetivos de modo a mediatizar uma nova concepção de educação e uma nova relação entre escola/ trabalho/ sociedade?

Nossa resposta a estas três indagações é afirmativa. Não há como mudar substantivamente o ensino, sem abalar o já instituído. É preciso revisitar as velhas questões e as velhas práticas, buscando renoválas, porém superando a nova aparência de mudança, os pequenos retoques, que apenas disfarçam as "marcas de um tempo", que teoricamente, dizemos querer negar. É preciso distinguir claramente a diferença entre o novo e a novidade em educação, especialmente nesta virada de século, onde se proclama o "fim das ideologias" e onde se pasteurizam as concepções de direito e cidadania.

\section{CAMINHO(S) POSSÍVEL(IS) PARA UMA PRÁTICA PEDAGÓGICA REFLEXIVA NA FORMAÇÃO DE PROFISSIONAIS NA ÁREA DE SAÚDE}

Formar profissionais críticos faz parte dos discursos e das metas propostas pelas instituições formadoras e dos que estão envolvidos com esta formação. No entanto, nem sempre é explicitado neste processo, como desenvolver e atingir estes propósitos, superando a retórica, efetivando medidas concretas.

$O$ que vai determinar se uma formação profissional se dá num sentido progressista, críticoreflexivo ou conservador e tecnicista, em grande parte, é o modo de entender e fazer a educação, de como ela é trabalhada em sala de aula, espaço de interação entre professores e alunos.

A ação educativa pode ser usada como meio de dominação ou libertação dos indivíduos. No espaço da dominação interessa formar sujeitos dependentes, não críticos, acomodados às informações recebidas, sem criatividade e capacidade de refletirem sobre a realidade que vivem ou onde irão atuar, o que é bastante interessante para os grupos que detém o poder, pois estes terão menores dificuldades de governar e manipular uma população passiva, não questionadora. No espaço que denominamos de libertador, entendemos uma formação de indivíduos críticos, independentes, questionadores, capazes de refletirem sobre suas realidades (educacional, social, política, econômica, cultural, etc.) e portanto, instrumentalizados para viabilizar as rupturas no instituído.
O processo pedagógico, que visa a construção do saber do indivíduo, deve estimular o ato reflexivo, desenvolvendo sua capacidade de observação, análise, crítica, autonomia de pensar e de idéias, ampliando os seus horizontes, tornando-o agente ativo nas transformações da sociedade, buscando interagir com a realidade na qual está inserido.

A educação assume, assim, uma função mediadora de uma prática social global e a nosso ver, a metodologia de formação necessária é aquela capaz de fazer o aluno compreender criticamente a prática social na qual vive e em que vai interagir profissionalmente (NÓVOA, 1991).

Nesta perspectiva, os alunos em formação se apropriam do saber produzido, sistematizado, mas de um saber que seja significativo como instrumento de cidadania.

Considerando esses pressupostos, no desenvolvimento do nosso trabalho, gostaríamos de ressaltar que ele não tem a pretensão de apontar fórmulas a serem seguidas no processo de formação de profissionais nas universidades. Pretendemos, sim, com estas reflexões, contribuir para desvelar, articular e aprofundar aspectos que permeiam este processo, procurando colaborar na formação de cidadãos reflexivos e críticos.

Contaremos, em nossas análises, com a contribuição de alguns teóricos da área da educação, que avançam em algumas questões que permeiam este processo, esta forma de ver e fazer educação.

Entendemos que a formação educacional dos indivíduos vai ocorrendo ao longo de suas vidas, e nela, a sala de aula assume um papel de destaque nas atividades educativas, constituindo-se em um espaço formal onde ocorre o processo de ensino. A prática pedagógica presente nas salas de aula, está permeada pelos aspectos histórico-políticos, pelas perspectivas científicopedagógicas, pelas análises e reflexões filosóficas, o que mostra a complexidade para tomá-la para análise. Desta prática pedagógica emerge, também, a possibilidade de uma educação mediadora, que se opõe à mistificação, modificando a imagem que o aluno (futuro profisional) tem de si e de suas relações com o trabalho, com o mundo.

Compartilhando e vivenciando esta prática pedagógica cotidiana, verificamos que ela está a exigir reais transformações; entretanto, entendemos que as mudanças no processo educativo, por si, não vão resolver as dificuldades e os desafios que os futuros profissionais enfrentarão nas instituições onde atuarão.

Os problemas existentes na formação e no exercício dos profissionais na área da saúde devem ser situados no contexto político-econômico e social, delineado anteriormente, exigindo, entre outras, mudanças curriculares, organizacionais, reestruturações 
de nossas práticas, bem como o engajamento nas lutas por condições mais favoráveis de trabalho.

A educação tem assumido um importante papel nas macropolíticas do Estado, como um fator significativo para a qualificação de recursos humanos requisitados pelo novo padrão de desenvolvimento internacional, onde se destaca a produtividade e a qualidade dos bens e produtos decisivos para a competição internacional.

Vários estudiosos apontam que para os futuros profissionais enfrentarem estas mudanças no mercado de trabalho, deverão possuir características e requisitos intelectuais básicos tais como autonomia, iniciativa, capacidade de resolução de problemas, criatividade, domínio da informática e de outras línguas.

Nossa compreensão de uma formação críticareflexiva, que tenha como principal objetivo formar um profissional orientado para a indagação, para a reflexão na ação, capaz de problematizar e portanto não alienado; capaz de evitar o verbalismo, o congelamento do real, o formalismo, a adaptação às estruturas, a compartimentalização do saber que contribui para a falta de domínio do processo, do produto e do sentido do próprio trabalho; não pode ficar alheia a essas expectativas colocadas pelo novo modo de produção. Entretanto, entendemos que nosso compromisso deva contemplar estas e outras preocupações.

Trilhamos caminhos onde se viabiliza aos futuros profissionais definir, formar e transformar a sua prática, levando-os a uma dinâmica de examinar, reexaminar e modificar suas concepções de mundo, sociedade e homem e intervir com novas ações.

Para desenvolver uma prática pedagógica que se quer reflexiva é necessário criar condições de colaboração e trabalho em equipe entre professor e alunos, facilitando a aplicação de estratégias, capazes de levá-los a diferentes formas de reflexão, como as mencionadas por GARCIA (1992, p. 64):

- a introspecção: entendida como reflexão interiorizada, pessoal onde são reconsiderados os pensamentos e os sentimentos, o que implica tomar uma certa distância das atividades diárias;

- o exame: onde são retomados e relacionados os acontecimentos e ações que já ocorreram, que estão ocorrendo ou que ocorrerão;

- a indagação: permite aos profissionais indagarem a sua prática, o seu cotidiano e identificar estratégias para melhorá-los;

- a espontaneidade: é a reflexão na ação, volta-se aos pensamentos dos profissionais no desenvolvimento de suas práticas, onde improvisam, resolvem problemas, tomam decisões;

- a auto-análise e a auto-crítica: pressupõem mudanças de aspectos interiores e pessoais tais como atitudes, valores, disposições.
Todas estas formas de reflexão implicam envolvimento e interação dos sujeitos que vivenciam o processo, consigo próprios e com os outros participantes.

GARCIA (1992, p.62-63), baseando-se em Dewey, aponta ainda algumas atitudes presentes numa prática reflexiva:

- "mentalidade aberta: definida como ausência de preconceitos, de parcialidades e de hábitos que limite a mente e a impeça de considerar novos problemas e de assumir novas idéias, integrando um desejo ativo de escutar mais do que um lado, de acolher os fatos independentes de suas fontes, de prestar atenção sem melindres a todas as alternativas, de reconhecer a possibilidade do erro mesmo em relação àquilo em que mais acreditamos. Isto implica escutar e respeitar diferentes perspectivas, atentando para alternativas possíveis, verificando a possibilidade de erro, investigando e analisando as evidências conflituosas, procurando várias respostas para a mesma questão, refletindo sobre a forma de melhorar o que já existe, etc.; - responsabilidade: trata-se principalmente da responsabilidade intelectual, considerando as conseqüências de um passo a ser dado, assegurando a integridade, a coerência e a harmonia daquilo em que se acredita, como também procurar os propósitos éticos e educativos da conduta e prática profissional;

- entusiasmo: entendido como predisposição para enfrentar a atividade com curiosidade, energia, capacidade de renovação e de luta contra a rotina."

Pollard \& Tann apud Garcia (1992), refletindo sobre destrezas necessárias para o professor desenvolver um ensino reflexivo, apontam algumas, tais como:

- destrezas empíricas: capacidade de realizar diagnóstico em relação à sala de aula e à escola, descrevendo situações, processos, causas e efeitos;

- destrezas analíticas: para analisar dados descritivos e construir uma teoria a partir deles;

- destrezas avaliativas: relacionadas com o processo de valoração, de emissão de juizos sobre as conseqüências dos projetos, propostas e a importância dos resultados alcançados;

- destrezas estratégicas: necessárias ao planejamento das ações;

- destrezas práticas: implica relacionar a análise com a prática, fins e meios;

- destrezas de comunicação: necessidade de comunicar e partilhar as suas idéias com outros, fomentando o trabalho e as discussões em grupo.

Trabalhar com as diferentes formas de reflexão, desenvolver nos alunos as destrezas e atitudes necessárias à reflexão, é um caminho a ser percorrido em todos os momentos de sala de aula. É possível e viável envolvêlos em atividades que permitam e possibilitem estes quesitos.

A importância de deixá-los chegar aos conceitos 
e não apresentá-los prontos, acabados; de mostrar diferentes visões e concepções sobre um determinado conhecimento, superando a linearidade; de contextualizar historicamente o conhecimento, fazendo-os perceber as mudanças que ele tem ao longo do tempo; de formar sínteses das principais idéias, conceitos e pensamentos diante da grande produção de conhecimentos, são caminhos possíveis ao ensino reflexivo que julgamos necessário aos novos tempos.

O texto é um pretexto para ir além e na leitura exercitar o diálogo, a dúvida; no debate, desenvolver os argumentos mas também a habilidade de ouvir o diferente, o novo; vivenciar experiências concretas com o espírito de um desbravador que observa cuidadosamente, que pondera, que toma decisões, que avalia, que refaz quantas vezes forem necessárias; estabelecer diálogos e interações entre a teoria e a prática; saber o significado e a fundamentação daquilo que aprendem, para poder compreender e contextualizar o exercício profissional nosso de cada dia.

Garantir que os alunos se apropriem de maneira significativa, crítica, criativa e duradoura do conhecimento acumulado, considerado fundamental, possibilita a geração de novos conhecimentos, a construção da cidadania e a transformação da realidade.

No processo pedagógico que se quer críticoreflexivo é fundamental a mobilização para o conhecimento, a construção do conhecimento, a elaboração e expressão da síntese do conhecimento, e isto acontece quando se propiciam espaços para desenvolvê-los, quando se vivenciam práticas significativas em sala de aula, quando há oportunidades de relacionar o conhecimento e a educação com a realidade profissional, política, econômica e social (VASCONCELLOS, 1996).

Ressaltamos ainda que no processo pedagógico que se quer crítico, a avaliação do processo de construção de um novo padrão de comportamentos e atitudes nos egressos da área da saúde, não pode ser regido pela lógica da classificação, da medição e do disciplinamento. Pelas relações de poder que impregnam as práticas avaliativas, nelas residem as maiores forças desaceleradoras do pensamento divergente, da autonomia intelectual, da leitura plural de uma realidade em constante evolução, sujeita portanto, à múltiplas interpretações e determinações (SORDI,1995; FREITAS, 1995; HOFFMAN 1994).

Trata-se pois de ressignificar a nossa prática pedagógica em sala de aula, com especial atenção à praxis avaliativa que fazemos junto e ensinamos aos futuros profissionais, se genuinamente quisermos fazer acontecer nos cenários da vida em que atuamos, a formação crítica que teoricamente defendemos.

Entendemos que esta transformação na lógica da formação dos profissionais na área da saúde, por si só, não garante mudanças na qualidade dos serviços oferecidos à população. Esta assistência assume uma complexidade que vai para além da qualidade dos profissionais que a executam. Vale ressaltar que "pesam" sobre a prestação dos serviços nas instituições, as determinações das grandes políticas sócio-econômicas, que por sua vez, definem o valor e o eixo das políticas de saúde, no contexto do projeto neoliberal. Portanto, a formação e ação dos profissionais da saúde, não devem se ater a um plano imediatista e linear, padecendo de um certo voluntarismo, sendo necessário buscar enfrentar tais problemas de forma organizada e politicamente situada.

\section{A POSSIBILIDADE DE ESCOLHAS: A HORA E A VEZ DA DECISÃO}

Defendemos a importância de nos posicionarmos politicamente em nossos espaços de atuação como formadores de recursos humanos em áreas nevrálgicas como saúde e educação, num mundo onde a lógica neoliberal parece imperar impunemente.

Cremos ser indispensável providenciarmos condições para que nossos alunos possam se apropriar de elementos que os qualifiquem para uma inserção profissional duplamente densa: quer no plano técnico, quer no plano ético.

Assim, a forma de organização de nossa prática pedagógica pode ser eloqüente nos valores que, de forma real ou oculta, ela veicula. É direito de cada um de nós, escolher o caminho a seguir. Parece-nos, entretanto, dever de ofício fazer essa opção de forma lúcida, evitando dissimular nossa intencionalidade política, qualquer que seja ela.

Ressaltamos que a formação crítico-reflexiva exige de nós uma tomada de posição clara, em favor da emancipação do homem, do resgate de suas possibilidades e potencialidades infinitas de vir-a-ser no mundo, com os outros, num esforço conjunto de construir e desfrutar da "qualidade social" de vida, contrapondo-se à decantada "qualidade total" defendida pelas empresas.

A formação de profissionais da saúde nesta virada do século, não pode prescindir da necessidade de se fazer escolhas, e assumir o ônus desta opção, não transgredindo valores e princípios teóricos, norteadores de um modelo de atenção à saúde, que para ser viável requer a ação de profissionais concretos, dispostos a intervir na realidade social, por desfrutarem de instrumentos teórico-políticoepistemológicos que os coloquem em condição privilegiada para enfrentar os desafios da nova ordem mundial, extraindo dela as vantagens, e usando-a em favor do homem e da humanidade, num plano ético-pedagógico inequívoco. 


\section{SUBSIDIES FOR A CRITICAL-REFLEXIVE PROFESSIONAL FORMATION IN THE HEALTH AREA AND THE CHALLENGE OF THE CHANGING CENTURY}

Change in the logic of health profissional formation is a demanding challenge for the new world order. The present study searches the problematical bases of reflexive-critical teaching in the area and its contribution for placing the profissional in the work market. This insertion must be regulated by the collective citizenship ethics and must also look forward to a confrontation, in an organized way, with the interests of the neoliberal project.

KEY WORDS: professional formation, critical-reflexive education, citizenship

\section{SUBSIDIOS PARA UNA FORMACIÓN PROFESIONAL CRÍTICA-REFLEXIVA EN EL ÁREA DE LA SALUD Y EL DESAFÍO DEL CÁMBIO DEL SIGLO}

El cambio de la lógica de la formación de los profesionales de la salud es una exigencia frente a los desafios del nuevo orden mundial. Este estudio busca problematizar las bases de la ensenãnza crítico-reflexiva en el área y su contribución para la inserción de los profesionales en el mercado de trabajo. Esta inserción debe ser regida por la ética de la ciudadanía colectiva y debe estar dispuesta a enfrentar de forma organizada los intereses del projecto neoliberal.

TÉRMINOS CLAVES: formación profesional, enseñanza crítico-reflexiva, ciudadanía

\section{REFERÊNCIAS BIBLIOGRÁFICAS}

01. FREITAS, L.C. Crítica da organização do trabalho pedagógico e da didática. Campinas: Papirus, 1995.

02. FRIGOTTO, G. Cidadania e formação técnico profissional: desafios neste fim de século. In: SILVA, L.H.et al. (org) Novos mapas culturais, novas perspectivas educacionais. Porto Alegre: Sulina, 1996. p. 137-164.

03. GARCIA, C.M. A formação de professores: novas perspectivas baseadas na investigação sobre o pensamento do professor. In: NOVOA, A. (coord). Os professores e a sua formação. Lisboa: Publ. Dom Quixote, 1992. p. 51-56.
04. HOFFMAN, J. Avaliação mediadora: uma prática em construção da pré escola à universidade. 3. ed. Porto Alegre: Educação e Realidade, 1994.

05. NÓVOA, A. (org) Profissão professor. Portugal: Porto Editora, 1991.

06. SORDI, M.R.L. A prática de avaliação no ensino superior: uma experiência na enfermagem. São Paulo: Cortez/PUCCamp, 1995.

07. VASCONCELlOS, C.S. Construção do conhecimento em sala de aula. 4. ed. São Paulo. 1996. (Cadernos Pedagógicos da Libertad, 2). 